УДК $54.061+54.062$

\title{
АНАЛИЗ СОСТАВА И СВОЙСТВ СЫРЬЯ БЕРЕЗОВОГО ГРИБА ЧАГИ, INONOTUS OBLIQUUS (PERS.) PILAT, СОБРАННОГО В ТОМСКОЙ ОБЛАСТИ
}

\author{
(ㄱ В.В. Хасанов, Ю.Г. Слижсов, А.А. Чумаков", С.В. Бажниа \\ Национальный исследовательский Томский государственный университет, \\ пр. Ленина, 36, Томск, 634050 (Россия).e-mail: anton.doktor.tomsk@mail.ru
}

\begin{abstract}
Проведено исследование состава тритерпеноидов и антиоксидантных свойств березового гриба чаги, Inonotus obliquus (Pers.) Pilat, собранного в Томской области. В сырье методом ГХ-МС идентифицированы тетрациклические тритерпеноиды ланостановой и эргостановой групп, некоторые из которых проявляют, по литературным данным, противоопухолевую активность. Методом, использующим модельную реакцию окисления сульфита натрия в диффузионной области, была измерена антиоксидантная активность водного экстракта чаги и сопоставлена с активностью галловой кислоты. Антиоксидантная активность не показала зависимости от степени измельчения сырья в изученном диапазоне размеров его частиц.
\end{abstract}

Ключевые слова: чага, Inonotus obliquus (Pers.) Pilat, тритерпеноиды, антиоксидантная активность, галловая кислота.

\section{Введение}

Березовый гриб чага, Inonotus obliquus (Pers.) Pilat, - средство народной медицины, известное в России с XII столетия [1]. Комплексные экстракты и индивидуальные компоненты гриба проявляют антиоксидантные, противоопухолевые, иммуностимулирующие и другие биологические свойства [2]. Состав и свойства природного сырья одного и того же биологического вида могут существенно различаться в зависимости от мест произрастания, времени сбора, способов переработки и других факторов. Так, при исследовании состава тритерпеноидов сырья чаги, собранного в разных регионах Китая и переработанного разными методами экстракции, были получены результаты, отличные друг от друга как качественно, так и количественно [3, 4]. В работе [5] авторы установили различие значений антиоксидантной активности разных партий сырья чаги и показали изменение антиоксидантной активности водного экстракта из одной и той же партии сырья при смене способа экстракции.

Целью нашей работы было исследование состава тритерпеноидов и антиоксидантных свойств сырья березового гриба чаги, собранного в Томской области.

\section{Экспериментальная часть}

Сбор и подготовка сырья. Сырье Inonotus obliquиs (Pers.) Pilat было собрано в сентябре 2013 года в Первомайском районе Томской области вдали от автомобильных трасс и населенных пунктов. Сбор

Хасанов Виктор Вазикович - кандидат химических наук, доцент кафедры органической химии,

e-mail: xasanov@chem.tsu.ru

Слижов Юрий Геннадьевич - кандидат химических наук, декан химического факультета, заведующий кафедрой органической химии, e-mail: dekanat@ xf.tsu.ru Чумаков Антон Александрович - врач-биохимик, магистрант кафедры органической химии, e-mail: anton.doktor.tomsk@mail.ru

Бажина Светлана Владимировна - директор ООО «ФПП РусЛана», e-mail: dekanat@xf.tsu.ru и подготовка сырья чаги осуществлялись в соответствии с требованиями Государственной фармакопеи XI [6]. После сушки и измельчения сырье с помощью ручных лабораторных сит было разделено на пять фракций: размер частиц менее 0,1 мм; 0,1-0,2 мм; 0,2-0,3 мм; 0,3-0,4 мм и более 0,4 мм (до 6 мм). Фракционирование сырья было проведено с целью дальнейшего анализа зависимости антиоксидантной активности от степени измельчения сырья.

\footnotetext{
* Автор, с которым следует вести переписку.
} 
Водная экстракция. Точная навеска (200 мг) каждой фракции, а также нефракционированного сырья, была смешана с 10 мл дистиллированной воды. Все шесть образцов одновременно настаивали при температуре $95^{\circ} \mathrm{C}$ в течение 2 часов при постоянном помешивании. После охлаждения водные вытяжки отделялись от шрота методами центрифугирования (5 минут, скорость 3500 мин $^{-1}$ ) и фильтрации (диаметр пор фильтра 450 нм). В дальнейшем экстракт из нефракционированного сырья был обезвожен с помощью ротационного испарителя при температуре бани $60{ }^{\circ} \mathrm{C}$, температуре отгоняемого пара $40{ }^{\circ} \mathrm{C}$ и остаточном давлении 70 мБар.

Измерение антиоксидантной активности (AOA) водных экстрактов и галловой кислоты проводилось методом, использующим модельную реакцию окисления сульфита натрия в диффузионной области [7]. Результаты для шести жидких образцов рассчитывались на массу навески сырья, для обезвоженного экстракта из нефракционированного сырья - на массу сухого остатка, для галловой кислоты (Sigma, США) - на массу ее навески. Галловая (3,4,5-тригидроксибензойная кислота) использовалась в качестве стандарта, с антиоксидантной активностью которого сопоставлялась активность водного экстракта чаги.

Пробоподготовка и анализ состава тритерпеноидов. Для анализа на тритерпеноиды были взяты образцы нативного сырья, высушенного водного экстракта и шрота, оставшегося после водной экстракции. Экстракцию нативного сырья проводили хлороформом и гексаном, шрота и сухого остатка водного извлечения - только хлороформом. Обработку образцов экстрагентами осуществляли в соотношении $1: 20$ (масса : масса) при воздействии ультразвука (частота 30 кГц, мощность 1-2 Вт/см²) в течение 15 мин при температуре $60{ }^{\circ} \mathrm{C}$, далее центрифугировали и надосадочную жидкость выпаривали досуха в токе азота при комнатной температуре. Полученные сухие остатки модифицировали реагентом Sylon HTP (Supelco) при нагревании до $60{ }^{\circ} \mathrm{C}$ в течение 30 мин. После охлаждения смесь центрифугировали (3 мин, 10000 мин $^{-1}$ ). Надосадочную жидкость анализировали методом ГХ-МС на оборудовании Agilent 7890/5975С. Газохроматографическое разделение осуществляли на кварцевой капиллярной колонке DB-5ms (фирмы J\&W), 30 м × 0,25 мм, толщина фазы 0,25 мкм в режиме программирования температуры: $130{ }^{\circ} \mathrm{C}\left(2\right.$ мин), $20{ }^{\circ} \mathrm{C} / \mathrm{Mин} \mathrm{до}$ $290{ }^{\circ} \mathrm{C}, 290{ }^{\circ} \mathrm{C}\left(25\right.$ мин). Температура испарителя $280{ }^{\circ} \mathrm{C}$, переходной линии $290{ }^{\circ} \mathrm{C}$, ионного источника $230{ }^{\circ} \mathrm{C}$, квадруполя $150{ }^{\circ} \mathrm{C}$. Скорость потока газа-носителя (гелий) составляла $1 \mathrm{~cm}^{3} /$ мин. Ввод пробы - без деления потока, 1 мкл. Детектирование - МСД 5975С, в режиме электронного удара при 70 эВ. Сканирование проводили в режиме развертки от 45 до 700 а.е.м. Тритерпеноиды в составе чаги были идентифицированы по полученным масс-спектрам. Для идентификации были использованы данные библиотек массспектров NIST 2008, Wiley и публикации [3]. В таблице 1 приведены масс-спектры TМС-производных обнаруженных нами тритерпеноидов.

Таблица 1. Масс-спектры ТМС-производных тритерпеноидов чаги, ЭУ 70 эВ

\begin{tabular}{|c|c|}
\hline Соединения & Масс-спектры, $m / z\left(I_{\text {отн }}, \%\right)$ \\
\hline 1 & 2 \\
\hline Инотодиол & $\begin{array}{l}\left.\text { 586( } \mathrm{M}^{+}, 0.7\right), 571(4), 517(25), 481(6), 427(21), 391(16), 337(89), 297(73), \\
281(12), 255(18), 229(27), 215(28), 201(14), 187(17), 171(42), 157(23), 145(18), \\
129(50), 119(20), 109(22), 95(18), 73(100), 55(8), 41(7)\end{array}$ \\
\hline Ланостерин & $\begin{array}{l}498\left(\mathrm{M}^{+}, 26\right), 483(21), 413(1), 393(78), 378(1), 351(2), 337(1), 323(2), 311(5), \\
297(2), 283(4), 269(4), 255(8), 241(15), 227(13), 215(13), 201(8), 187(15), \\
173(15), 159(15), 145(17), 129(50), 109(40), 95(33), 81(24), 69(100), 55(35), \\
41(32)\end{array}$ \\
\hline Траметеноловая кислота & $\begin{array}{l}\left.\text { 600( } \mathrm{M}^{+}, 15\right), 585(29), 518(3), 495(18), 467(7), 405(6), 377(23), 281(26), 255(10), \\
241(10), 227(10), 213(10), 199(10), 189(18), 173(15), 158(25), 145(18), 129(52), \\
119(18), 107(16), 95(18), 73(100), 55(10), 41(8)\end{array}$ \\
\hline 3ß-Гидроксиланоста-8,24-диен-21-аль & $\begin{array}{l}512\left(\mathrm{M}^{+}, 7\right), 497(11), 483(4), 430(4), 407(29), 389(11), 360(7), 325(3), 281(18), \\
267(3), 255(11), 241(7), 227(11), 215(10), 203(11), 189(18), 173(16), 159(18), \\
145(18), 129(54), 119(26), 107(35), 95(30), 73(100), 55(22), 41(22)\end{array}$ \\
\hline Эргостерин & $\begin{array}{l}468\left(\mathrm{M}^{+}, 28\right), 453(2), 378(16), 363(100), 337(72), 326(2), 279(2), 265(4), 253(54), \\
237(11), 225(10), 211(39), 199(23), 183(22), 169(27), 157(39), 143(38), 129(35), \\
119(35), 117(13), 105(17), 91(22), 81(37), 73(87), 69(76), 55(62), 43(54)\end{array}$ \\
\hline Эргоста-7-ен-3 $\beta$-ол & $\begin{array}{l}\text { 472(M+, 94), 457(23), 367(17), 345(7), 303(7), 255(94), 229(28), 213(49), } \\
201(11), 199(15), 187(11), 185(11), 171(15), 159(21), 147(32), 133(28), 119(32), \\
107(45), 95(43), 75(100), 55(53), 43(89)\end{array}$ \\
\hline
\end{tabular}


Окончание таблиць 1

\begin{tabular}{|c|c|}
\hline 1 & 2 \\
\hline 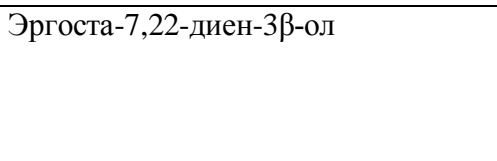 & $\begin{array}{l}470\left(\mathrm{M}^{+}, 27\right), 455(17), 372(13), 343(66), 329(13), 318(9), 255(68), 241(11), \\
229(36), 213(27), 199(11), 187(19), 173(15), 159(36), 147(35), 145(36), 133(38), \\
119(32), 107(48), 105(49), 95(40), 91(43), 81(68), 75(100), 69(100), 55(96), \\
43(60)\end{array}$ \\
\hline Эргоста-5,7,9(11),22-тетраен-3ß-ол & $\begin{array}{l}\left.\text { 466( } \mathrm{M}^{+}, 9\right), 451(5), 435(2), 376(24), 361(9), 325(9), 251(100), 235(10), 223(10), \\
\text { 209(18), 195(18), 181(13), 169(13), 155(13), 141(9), 129(10), 115(4), 95(8), } \\
73(57), 55(38), 43(28)\end{array}$ \\
\hline Эргоста-5,7,22,24(28)-тетраен-3ß-ол & $\begin{array}{l}466\left(\mathrm{M}^{+}, 89\right), 451(6), 377(6), 365(18), 339(18), 326(4), 299(4), 287(4), 267(4), \\
251(15), 237(7), 225(7), 211(18), 195(15), 183(17), 169(17), 157(18), 143(18), \\
129(15), 117(11), 105(12), 95(15), 73(100), 55(56), 43(55)\end{array}$ \\
\hline
\end{tabular}

\section{Обсуждение результатов}

Измерение АОА водных экстрактов чаги и галловой кислотыл. Результаты измерения АОА чаги и стандарта приведены в таблице 2. Как видим, антиоксидантная активность не показала четкой зависимости от степени измельчения сырья, так как результаты для шести жидких образцов близки между собой. Поэтому для получения из чаги вытяжки антиоксидантного действия нет необходимости получения сильно измельченных фракций. Расчет АОА на массу обезвоженного остатка дает результат, позволяющий учесть удаление шрота после экстракции. Измерение активности стандартного соединения - галловой кислоты дает возможность выразить АОА чаги объективным способом, не зависящим от методики измерения АОА и позволяющим сопоставлять результаты, получаемые разными методами оценки АОА, - в эквивалентах галловой кислоты. Так, антиоксидантная активность сухого водорастворимого экстракта чаги эквивалентна

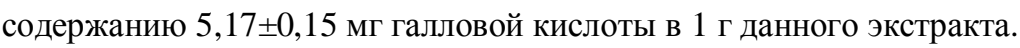

Состав тритерпеноидов чаги. В таблице 3 приведены результаты анализа чаги на тритерпеноиды, а также литературные данные по этому вопросу. Согласно полученным данным, главным тритерпеноидным соединением в составе чаги, собранной в Томской области, является инотодиол, составляя более $50 \%$ от суммы тритерпеноидов, извлекаемой органическими экстрагентами из нативного сырья. Инотодиол и три следующих в таблице 3 вещества относятся к тетрациклическим тритерпеноидам ланостановой группы (рис. 1). Практически все тритерпеноиды при водном экстрагировании сырья остаются в составе шрота. При этом наблюдается концентрирование этих соединений, что, очевидно, обусловлено выходом из сырья водорастворимых компонентов. Это приводит к повышению чувствительности анализа, так как в шроте обнаруживается больше соединений. Заметно влияние вида органического экстрагента на извлекаемость тритерпеноидов. Так, траметеноловая кислота и соответствующий ей альдегид лучше извлекаются хлороформом, чем гексаном. Кроме ланостановых тетрациклических тритерпеноидов в чаге обнаруживаются в гораздо меньшем содержании тритерпеноиды группы эргостана - эргостерин (рис. 2) и интермедиаты его биосинтеза из предшественника - ланостерина. При сравнении полученных результатов с литературными данными можно сделать вывод, что ланостерин и его производное инотодиол (гидроксилирование в 22-м положении) составляют в среднем около $70 \%$ всех тритерпеноидов чаги. Однако в двух исследованиях $[3,4]$ показаны противоположные соотношения в содержании этих двух соединений. Наши результаты по этому параметру совпадают с данными [4]: содержание инотодиола превышает содержание ланостерина приблизительно в 3,5 раза, что положительно характеризует потенциальную фармакологическую ценность сырья, так как именно инотодиол, по литературным данным, показывает противоопухолевую активность [8-10].

Таблица 2. Антиоксидантная активность водных экстрактов чаги и галловой кислоты

\begin{tabular}{|c|c|c|}
\hline \multicolumn{2}{|c|}{ Образцы } & Антиоксидантная активность \\
\hline \multirow{5}{*}{\multicolumn{2}{|c|}{$\begin{array}{c}\text { Фракция <0,1 мм } \\
\text { Фракция 0,1-0,2 мм } \\
\text { Фракция 0,2-0,3 мм } \\
\text { Фракция 0,3-0,4 мм } \\
\text { Фракция >0,4 мм (до } 6 \text { мм) }\end{array}$}} & $202 \pm 20 \mathrm{M \Gamma}^{-1}$ \\
\hline & & $215 \pm 20 \mathrm{M \Gamma}^{-1}$ \\
\hline & & $226 \pm 20 \mathrm{M \Gamma}^{-1}$ \\
\hline & & $200 \pm 20 \mathrm{M \Gamma}^{-1}$ \\
\hline & & $217 \pm 20 \mathrm{M \Gamma}^{-1}$ \\
\hline \multirow[t]{2}{*}{ нефракционированное сырье } & жидкий экстракт & $219 \pm 20 \mathrm{M \Gamma}^{-1}$ \\
\hline & обезвоженный экстракт & $776 \pm 25 \mathrm{M \Gamma}^{-1}$ \\
\hline \multicolumn{2}{|c|}{ Галловая кислота (стандарт) } & $150 \pm 15$ мкг $^{-1}$ \\
\hline
\end{tabular}


Таблица 3. Состав и содержание тритерпеноидов в сырье чаги, собранном в Томской области, в сравнении с литературными данными

\begin{tabular}{|c|c|c|c|c|c|c|}
\hline \multirow{2}{*}{ Тритерпеноиды } & \multicolumn{4}{|c|}{ Образцы чаги, собранной в Томской области } & \multicolumn{2}{|c|}{$\begin{array}{c}\text { Сравнение с лите- } \\
\text { ратурными дан- } \\
\text { ными (Китай) }\end{array}$} \\
\hline & $\begin{array}{c}\text { Нативное сырье, } \\
\text { хлороформный } \\
\text { экстракт }\end{array}$ & $\begin{array}{c}\text { Нативное сырье, } \\
\text { гексановый } \\
\text { экстракт }\end{array}$ & Шрот & $\begin{array}{c}\text { Сухой остаток } \\
\text { водного } \\
\text { экстракта }\end{array}$ & [3] & [4] \\
\hline Инотодиол & $56(14,8) *$ & $61,5(16,5)$ & $46(26,2)$ & $100(1,8)$ & 25,4 & 58,7 \\
\hline Ланостерин & $16(4,2)$ & $19,5(5,2)$ & $11(6,2)$ & - & 45,5 & 16,7 \\
\hline Траметеноловая кислота & $14,5(3,8)$ & $4,0(1,1)$ & $17,2(9,8)$ & - & - & 7,7 \\
\hline $\begin{array}{l}\text { 3及-Гидроксиланоста-8,24- } \\
\text { диен-21-аль }\end{array}$ & $9,0(2,4)$ & $6,3(1,7)$ & $10(5,7)$ & - & - & 1,4 \\
\hline Эргостерин & $3,0(0,8)$ & $5,2(1,4)$ & $7,0(4,0)$ & - & 4,3 & 0,8 \\
\hline 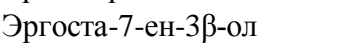 & $0,6(0,2)$ & $1,8(0,5)$ & $4,0(2,3)$ & - & - & 0,25 \\
\hline Эргоста-7,22-диен-3ß-ол & $0,5(0,17)$ & $1,7(0,4)$ & $2,9(1,6)$ & - & 2,5 & 1,0 \\
\hline 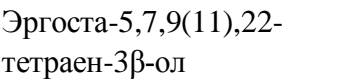 & - & - & $1,6(0,8)$ & - & 6,5 & - \\
\hline $\begin{array}{l}\text { Эргоста-5,7,22,24(28)- } \\
\text { тетраен-3ß-ол }\end{array}$ & - & - & $0,3(0,2)$ & - & - & - \\
\hline
\end{tabular}

* Первая цифра - \% от суммы тритерпеноидов, вторая - площадь хроматографического пика соединения (в \% после интегрирования), эквивалентная содержанию соединения в образце; по литературным данным - только относительный состав тритерпеноидов, \%.

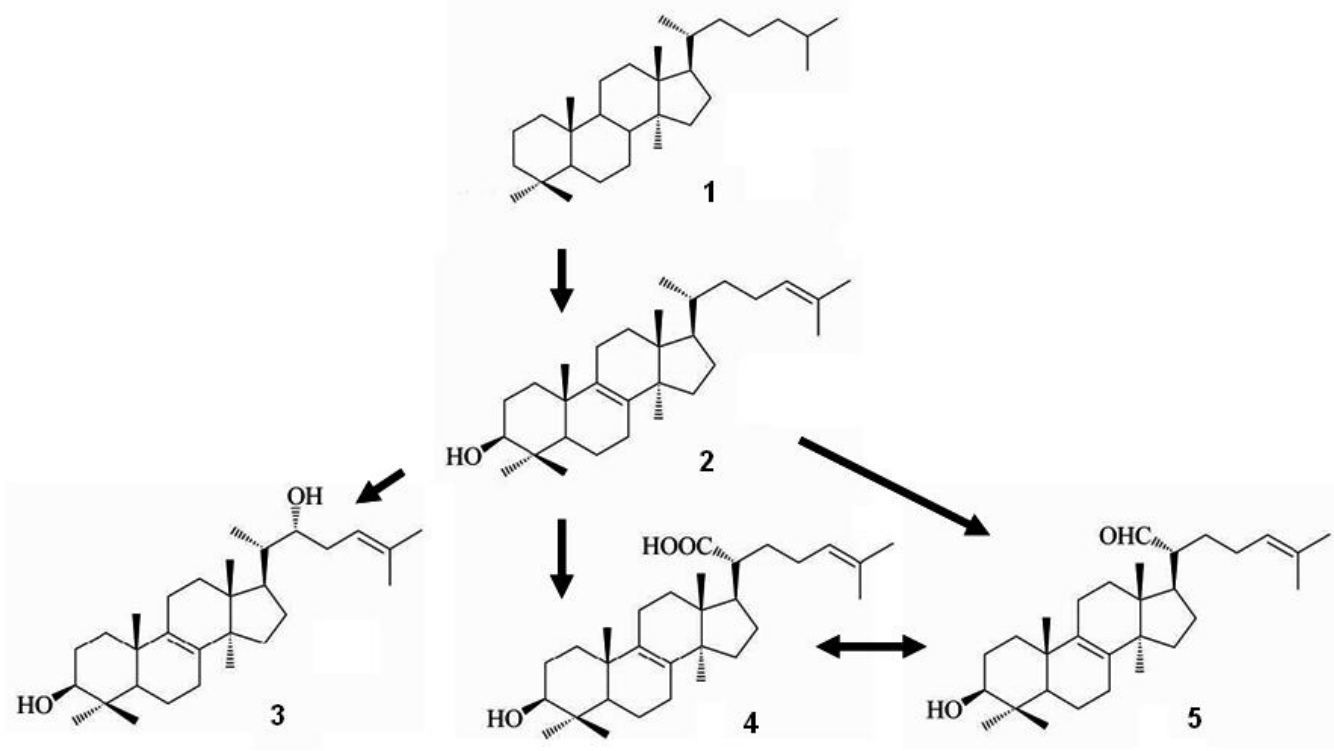

Рис. 1. Взаимосвязь строения тетрациклических ланостановых тритерпеноидов чаги. 1 - ланостан,

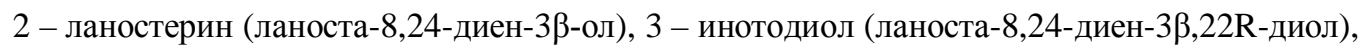
4 - траметеноловая кислота (3ß-гидроксиланоста-8,24-диен-21-овая кислота), 5 - $3 \beta$-гидроксиланоста8,24-диен-21-аль (альдегид, соответствующий траметеноловой кислоте)<smiles>CC(C)[C@H](C)/C=C/[C@H](C)[C@H]1CCC2C3=CC=C4C[C@@H](O)CC[C@]4(C)C3CC[C@]21C</smiles>

Рис. 2. Строение эргостерина

\section{Выводы}

1. Исследована антиоксидантная активность водного экстракта чаги. Показано отсутствие зависимости АОА от степени измельчения сырья, поэтому для получения из чаги вытяжки антиоксидантного действия нет необходимости получения сильно измельченных фракций. По полученным нами данным, антиоксидантная активность сухого водорастворимого экстракта сырья чаги, собранного в Томской области, эквивалентна содержанию $5,17 \pm 0,15$ мг галловой кислоты в 1 г данного экстракта. 
2. Исследован состав тетрациклических тритерпеноидов чаги. Преобладание среди этих соединений инотодиола, обладающего противоопухолевыми свойствами, положительно характеризует потенциальную фармакологическую ценность сырья чаги, собранного в Томской области.

3. Таким образом, сырье березового гриба чаги, Inonotus obliquus (Pers.) Pilat, собранное в Томской области, может быть источником получения вытяжки антиоксидантного действия и соединений потенциального противоопухолевого действия.

\section{Список литературы}

1. Shikov A.N., Pozharitskaya O.N., Makarov V.G., Wagner H., Verpoorte R., Heinrich M. Medicinal Plants of the Russian Pharmacopoeia; their history and applications // Journal of Ethnopharmacology. 2014. Vol. 154. N3, Pp. 481-536.

2. Song F.Q., Liu Y., Kong X.S., Chang W., Song G. Progress on understanding the anticancer mechanisms of medicinal mushroom: Inonotus obliquus // Asian Pacific Journal of Cancer Prevention. 2013. Vol. 14. N3. Pp. 1571-1578.

3. Zheng W.F., Liu T., Xiang X.Y., Gu Q. Sterol composition in field-grown and cultured mycelia of Inonotus obliquus // Acta pharmaceutica Sinica. 2007. Vol. 42. N7. Pp. 750-756.

4. Liu C., Zhao C., Pan H.H., Kang J., Yu X.T., Wang H.Q., Li B.M., Xie Y.Z., Chen R.Y. Chemical constituents from Inonotus obliquus and their biological activities // Journal of Natural Products, 2014. Vol. 77. N1. Pp. 35-41.

5. Сысоева М.А., Кузнецова О.Ю., Гамаюрова В.С., Суханов П.П., Зиятдинова Г.К., Будников Г.К. Исследование золя водных извлечений чаги. IV. Антиоксидантная активность. Влияние способа извлечения и применение комплексонов, гидрооксида натрия // Химия растительного сырья. 2005. №1. С. 41-47.

6. Государственная фармакопея СССР: Выпуск 2. Общие методы анализа. Лекарственное растительное сырье. M., 1989. 243 c.

7. Хасанов В.В., Рыжова Г.Л., Мальцева Е.В. Исследование антиокислительных свойств соединений с использованием реакции окисления сульфита натрия // Химия растительного сырья. 2004. №3. С. 77-85.

8. Nomura M., Takahashi T., Uesugi A., Tanaka R., Kobayashi S. Inotodiol, a lanostane triterpenoid, from Inonotus obliquus inhibits cell proliferation through caspase-3-dependent apoptosis // Anticancer Research. 2008. Vol. 28. N5A. Pp. 2691-2696.

9. Zhong X.H., Wang L.B., Sun D.Z. Effects of inotodiol extracts from Inonotus obliquus on proliferation cycle and apoptotic gene of human lung adenocarcinoma cell line A549 // Chinese journal of integrative medicine. 2011. Vol. 17. N3. Pp. 218-223.

10. Zhao L.W., Zhong X.H., Yang S.Y., Zhang Y.Z., Yang N.J. Inotodiol inhabits proliferation and induces apoptosis through modulating expression of cyclinE, p27, bcl-2, and bax in human cervical cancer HeLa cells // Asian Pacific Journal of Cancer Prevention. 2014. Vol. 15. №7. Pp. 3195-3199.

Поступило в редакциюю 16 ноября 2014 г. 
Khasanov V.V., Slizhov Yu.G., Chumakov A.A. ${ }^{*}$, Bazhina S.V. ANALYSIS OF THE COMPOSITION AND PROPERTIES OF RAW BIRCH MUSHROOM, INONOTUS OBLIQUUS (PERS.) PILAT, COLLECTED IN THE TOMSK REGION

National Research Tomsk State University, pr. Lenina, 36, Tomsk, 634050 (Russia), e-mail: anton.doktor.tomsk@mail.ru

Triterpenoid content and antioxidant activity of raw birch mushroom, Inonotus obliquus (Pers.) Pilat, collected in the Tomsk region were studied. Lanostane and ergostane tetracyclic triterpenoids were identified in raw material by GC-MS. Some of these compounds are biologically active. For instance, inotodiol was reported to exhibit antitumor activity. The antioxidant activity of aqueous extract was measured and expressed in equivalents of gallic acid. The antioxidant activity showed no dependence on the degree of raw material grinding in the studied particle size range from $<0,1$ to $4-6 \mathrm{~mm}$.

Keywords: birch mushroom, Inonotus obliquus (Pers.) Pilat, triterpenoids, antioxidant activity, gallic acid.

\section{References}

1. Shikov A.N., Pozharitskaya O.N., Makarov V.G., Wagner H., Verpoorte R., Heinrich M. Journal of Ethnopharmacology, 2014, vol. 154, no. 3, pp. 481-536.

2. Song F.Q., Liu Y., Kong X.S., Chang W., Song G. Asian Pacific Journal of Cancer Prevention, 2013, vol. 14, no. 3, pp. 1571-1578.

3. Zheng W.F., Liu T., Xiang X.Y., Gu Q. Acta pharmaceutica Sinica, 2007, vol. 42, no. 7, pp. 750-756.

4. Liu C., Zhao C., Pan H.H., Kang J., Yu X.T., Wang H.Q., Li B.M., Xie Y.Z., Chen R.Y. Journal of Natural Products, 2014, vol. 77, no. 1, pp. 35-41.

5. Sysoeva M.A., Kuznecova O.Ju., Gamajurova V.S., Suhanov P.P., Zijatdinova G.K., Budnikov G.K. Himija rastitel'nogo syr'ja, 2005, no. 1, pp. 41-47. (in Russ.).

6. Gosudarstvennaja farmakopeja SSSR: Vypusk 2. Obshhie metody analiza. Lekarstvennoe rastitel'noe syr'e. [The State pharmacopoeia of the USSR: Issue 2. General methods of analysis. Medicinal herbs]. Moscow, 1989. 243 p. (in Russ.).

7. Hasanov V.V., Ryzhova G.L., Mal'ceva E.V. Himija rastitel'nogo syr'ja, 2004, no. 3, pp. 77-85. (in Russ.).

8. Nomura M., Takahashi T., Uesugi A., Tanaka R., Kobayashi S. Anticancer Research, 2008, vol. 28, no. 5A, pp. 2691-2696.

9. Zhong X.H., Wang L.B., Sun D.Z. Chinese journal of integrative medicine, 2011, vol. 17, no. 3, pp. $218-223$.

10. Zhao L.W., Zhong X.H., Yang S.Y., Zhang Y.Z., Yang N.J. Asian Pacific Journal of Cancer Prevention, 2014, vol. 15, no. 7, pp. 3195-3199.

Received November 16, 2014

Revised December 17, 2014

\footnotetext{
* Corresponding author.
} 